Special Issue of the 8th International Advances in Applied Physics and Materials Science Congress (APMAS 2018)

\title{
Mechanical Properties of Quartz-Added PP Based Composites Produced by High Speed Thermo-Kinetic Mixer
}

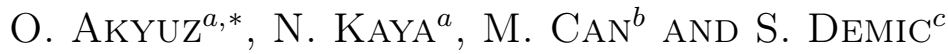

${ }^{a}$ İzmir Katip Çelebi University, Institude of Science, Department of Material Sience and Engineering, İzmir, Turkey

${ }^{b}$ İzmir Katip Çelebi University, Engineering and Architecture Faculty, Department of Engineering Science,

İzmir, Turkey

${ }^{c}$ İzmir Katip Çelebi University, Engineering and Architecture Faculty,

Department of Material Sience and Engineering, İzmir, Turkey

\begin{abstract}
Micronized quartz powders reinforced polypropylene (PP) composites were fabricated by using high speed thermo-kinetic mixer. The effect of micronized quartz on the mechanical properties of PP composites was investigated. Mechanical tests were carried out to determine tensile and flexural properties of composites. Dynamic Mechanical Analysis of composites was performed to determine their thermo-mechanical properties, such as storage modulus and loss modulus. The results indicate that the tensile strength of PP decreased with addition of micronized quartz. Flexural strength, tensile modulus and flexural modulus of PP increased with the addition of $10 \mathrm{wt} \%$ micronized quartz.
\end{abstract}

DOI: 10.12693/APhysPolA.135.1045

PACS/topics: polypropylene, quartz, composites, mechanical properties

\section{Introduction}

Thermoplastic based composites offer several advantages such as low density, high toughness, relative ease of manufacture and recyclability. Polypropylene PP is one of the most widely used polymer materials in the thermoplastic industry [1]. But polypropylene still need mechanical properties enhancement to enlarge its applications as engineering plastics [2].

Composite materials are the main substitute for the conventional engineering materials due to its good characteristics of strength to density, low-cost, eco-friendly manufacturing processes [3]. In the past decade, polymer matrix composites have replaced many conventional materials due to their better mechanical properties like corrosion resistance, wear resistance, better strength to weight ratio, better stiffness etc [4]. In general, the physical and mechanical properties of the composites depend on various factors such as the composition, their interactions and the operating conditions [5]. PP based composites have been already used in many industrial applications [6].

The objective of this study is to examine the influence of micronized quart and silanized quartz on the mechanical properties of quartz powders reinforced PP composites. In the study, quartz was used as a reinforcement material in PP composites. Quartz with various weight fractions was blended with PP using a high speed thermokinetic mixer.

*corresponding author; e-mail: orhanakyuz@yahoo.com

\section{Materials and equipment}

\subsection{Materials}

In this research, Petoplen MH 418 polypropylene that was supplied from Petkim with $25 \mathrm{~kg}$ polyethylene sacks was used. In this study, micronized quartz (MQ) powder obtained from quartz quarried at the mines of Pomza Export Mining Industry and Trade Co. in the region of Salihli Kaletepe and the silanized quartz (SQ) with surface modification agent obtained from Quarzwerke Group was applied. Also, MQ powder taken from Pomza was used as filling material in polymer matrix composite materials after it has been modified with four different surface agent. The result of particle size analysis of $\mathrm{MQ}$ powder is indicated in Table I.

TABLE I

Particle ratio of micronized quartz powders.

\begin{tabular}{c|c}
\hline \hline Size $[\mu \mathrm{m}]$ & Ratio $[\%]$ \\
\hline$>75$ & $\max .1$ \\
$75 \rightarrow 63$ & $0-4$ \\
$63 \rightarrow 45$ & $10-15$ \\
$<45$ & $80-85$
\end{tabular}

MQ powder is widely used as filling material for insulation applications in electricity sector because of its low electrical conductivity, high abrasion and corrosion resistance. The most important feature that should be considered when it is used as the epoxy filling material in respect of the insulating properties is the amount of iron and iron compounds impurities. Chemical composition of MQ powders used in this study is given in Table II. 
TABLE II

Chemical analysis of micronized quartz powders [\%].

\begin{tabular}{l|c|c|c|c|c|c}
\hline \hline $\mathrm{SiO}_{2}$ & $\mathrm{Fe}_{2} \mathrm{O}_{3}$ & $\mathrm{Al}_{2} \mathrm{O}_{3}$ & $\mathrm{TiO}_{2}$ & $\mathrm{CaO}$ & $\mathrm{K}_{2} \mathrm{O}$ & others \\
\hline 99.410 & 0.040 & 0.200 & 0.002 & 0.160 & 0.020 & 0.080
\end{tabular}

\subsection{Quartz surface modification process}

Firstly, a liter of aqueous solution containing $5 \mathrm{wt} \%$ of alcohol was prepared in the plastic beaker. The plastic beaker was placed on a magnetic stirrer. $\mathrm{pH}$ value was measured. Acetic acid was slowly added to the beaker. Once $\mathrm{pH}$ value remained at the ideal level (3-3.5), $1.5 \mathrm{~mL}$ of the modification agent was added to the aqueous solution and stirred for $60 \mathrm{~min}$ at $500 \mathrm{rpm}$. At the end of this time, $150 \mathrm{~g}$ of MQ powder was added into the solution. The magnetic stirrer speed was then accelerated to $800 \mathrm{rpm}$ and the quartz was mixed in the solution during 90 minutes. Next the magnetic stirrer was turned off and the solution was drained off with a paper filter to obtain surface modified quartz powder. This powder was dried at $110^{\circ} \mathrm{C}$ during $4 \mathrm{~h}$.

\subsection{Production of quartz reinforced PP based composite materials}

Composites were produced by high speed thermokinetic mixer at different particle/thermoplastic ratios (0-40 wt\%). Prior to production, appropriate quantities of particles and thermoplastic granules were weighed separately to get the desired ratio. Mixtures were placed in the mixing chamber of the mixer and the chamber was safely sealed. Thereafter, the material production was carried out via operation of mixer. Composite mixing rates are given in Table III.

\section{TABLE III}

Composite mixing rates and short names.

\begin{tabular}{l|c}
\hline \hline Composite mixing ratio & Short name \\
\hline $10 \% \mathrm{MQ}+90 \% \mathrm{PP}$ & $10 \mathrm{MQ}$ \\
$20 \% \mathrm{MQ}+80 \% \mathrm{PP}$ & $20 \mathrm{MQ}$ \\
$30 \% \mathrm{MQ}+70 \% \mathrm{PP}$ & $30 \mathrm{MQ}$ \\
$10 \% \mathrm{SQ}+90 \% \mathrm{PP}$ & $10 \mathrm{SQ}$ \\
$20 \% \mathrm{SQ}+80 \% \mathrm{PP}$ & $20 \mathrm{SQ}$ \\
$30 \% \mathrm{SQ}+70 \% \mathrm{PP}$ & $30 \mathrm{SQ}$ \\
$40 \% \mathrm{SQ}+60 \% \mathrm{PP}$ & $40 \mathrm{SQ}$ \\
Coatosil-2287 MQ $10 \%+90 \% \mathrm{PP}$ & 2287 \\
Coatosil-MP200 MQ $10 \%+90 \% \mathrm{PP}$ & $\mathrm{MP} 200$ \\
Silquest A-187 MQ $10 \%+90 \% \mathrm{PP}$ & $\mathrm{A} 187$ \\
Vemab A-110 MQ $10 \%+90 \% \mathrm{PP}$ & $\mathrm{A} 110$
\end{tabular}

\section{Results and discussion}

A universal tensile testing machine (Shimadzu AG-IC) with a load cell of $5 \mathrm{kN}$ was used to determine the mechanical properties of the produced composites. Tensile tests and flexural tests were performed according to ASTM D638 and ASTM D790 standards respectively. The head speed is $50 \mathrm{~mm} / \mathrm{min}$ in the tensile test and the head speed is $1 \mathrm{~mm} / \mathrm{min}$ in the flexural test. Mechanical properties such as tensile strength, modulus of elasticity, flexural strength and flexural modulus of the composites were determined.

The tensile test results for each of the samples produced are given in 4 measurement averages and the flexural test results in 3 measurement averages. The tensile test results of the produced composite specimens are given in Table IV.

Composites tensile test results.

TABLE IV

\begin{tabular}{l|c|c|c|c|c|c|c|c|c|c|c|c}
\hline \hline Sample & PP & 10MQ & 20MQ & 30MQ & 10SQ & 20SQ & 30SQ & 40SQ & 2287 & MP200 & A187 & A110 \\
\hline Tensile strength [Mpa] & 34.2 & 29.3 & 29.0 & 26.3 & 32.4 & 30.1 & 28.5 & 24.3 & 32.4 & 32.1 & 31.8 & 32.4 \\
Tensile modulus [MPa] & 823 & 1240 & 1170 & 1337 & 1165 & 1268 & 1509 & 1397 & 960 & 986 & 974 & 1064
\end{tabular}

Tensile strength and tensile modulus results of MQ doped composite samples produced in high speed thermokinetic mixer are given in Table IV. According to it, quartz additive reduces the tensile strength of $\mathrm{PP}$ material. While tensile strength of $\mathrm{PP}$ is $34.20 \mathrm{MPa}$, tensile strength of $20 \mathrm{MQ}$ is $29.30 \mathrm{MPa}$, and of $30 \mathrm{MQ}$ is $26.28 \mathrm{MPa}$. As it is seen from the results, the tensile strength decreases as the MQ amount increases in the composite. The tensile strength of PP decreases approximately $14.33 \%$ for $10 \mathrm{wt} \%$ MQ additive.

When the results are examined, it is seen that the tensile strength decreases with the increase of SQ amount also. The tensile strength of the 10SQ sample is approximately $10 \%$ higher $(32.70 \mathrm{MPa})$ when it is compared to the 10MQ composite sample with a tensile strength of 29.30 MPa. This is due to the fact that commercial SQ powders provide better matrix-filling interfacial alignment with PP matrix by comparision with MQ powders.

The decrease in tensile strength toward the PP matrix material is due to the fact that the additive material cannot be wetted sufficiently by the matrix material, the powders are not sufficiently dispersed and agglomerates. The adhesion between the matrix and the additive material is poor. The tensile strength of the filled PP decreases gradually due to aggregation of quartz powder and growing presence of micropores within the PP matrix with the increase of the filling rate. 
Composites flexural test results.

TABLE V

\begin{tabular}{c|c|c|c|c|c|c|c|c|c|c|c|c}
\hline \hline Samples & PP & 10MQ & 20MQ & 30MQ & 10SQ & 20SQ & $30 \mathrm{SQ}$ & $40 \mathrm{SQ}$ & 2287 & MP200 & A187 & A110 \\
\hline Flexural strength [Mpa] & 48,3 & 53,5 & 50,0 & 43,8 & 51,1 & 47,6 & 44,0 & 39,8 & 48,1 & 49,5 & 49,1 & 50,1 \\
Flexural modulus [Mpa] & 1413 & 1840 & 2078 & 2173 & 1685 & 1897 & 2037 & 2470 & 1574 & 1796 & 1815 & 1619
\end{tabular}

Table IV gives tensile test results of composite specimens with quartz powders treated with 4 different surface modifying agents of forms are seen. It has been observed that the tensile strength of composite specimens using modified quartz powders increases compared to $10 \%$ micronized quartz composites. This is the promoted result of the surface modification process and the improvement of the filler-matrix interface compatibility.

The flexural test results of the produced composite specimens are given in Table $\mathrm{V}$.

As shown in Table $\mathrm{V}$, the flexural strength of the PP matrix material is about $48 \mathrm{MPa}$. Composite samples with $10 \%$ and $20 \%$ MQ additive have a higher flexural strength than PP. However, a dramatic decrease in the flexural strength of the composite sample with $30 \%$ contribution is observed. All composite specimens have higher flexural modulus than PP. With increase of the contribution rate the flexural modulus increases also. The flexural strength PP with $10 \%$ addition of SQ is higher than for the matrix material, however for bigger contribution rates it tend to decrease. The flexural modulus continues to increase with the growing amount of the additive. The flexural strength of the modified quartzdoped composite specimens shows very low increase with additive quantity. Nevertheless, this effect is more pronouncede for the flexural modulus.

The storage modulus and loss modulus of PP and quartz powder reinforced composites were evaluated using a dynamic mechanical analyzer (TA Instruments, DMA Q800). Single cantilever was used and multi frequency-strain modulus mode was selected to analyze all specimens between the temperatures of 25 and $130^{\circ} \mathrm{C}$ in air atmosphere. DMA looks at the modulus of elasticity or the ratio of mechanical stress to relative deformation. The storage modulus $\left(E^{\prime}\right)$ and the loss modulus $\left(E^{\prime \prime}\right)$ were determined from the DMA tests. E0 represents the stiffness of a viscoelastic material, which is proportional to the elastic energy stored elastically and is reversible.

Storage moduli of PP and quartz reinforced PP composites versus temperature as a function of quartz weight fractions are given in Fig. 1. The storage modulus decreases with increasing temperature due to an energy dissipation phenomenon involving cooperative motions of the polymer chain. Comparing the PP and the MQ reinforced $\mathrm{PP}$ composites with different $\mathrm{MQ}$ weight fractions at temperatures from 37 to $125^{\circ} \mathrm{C}$, it is easy to find that the modulus of the composites containing 30 wt\% MQ was higher than the other specimens, although it decreased dramatically by increasing temperature.
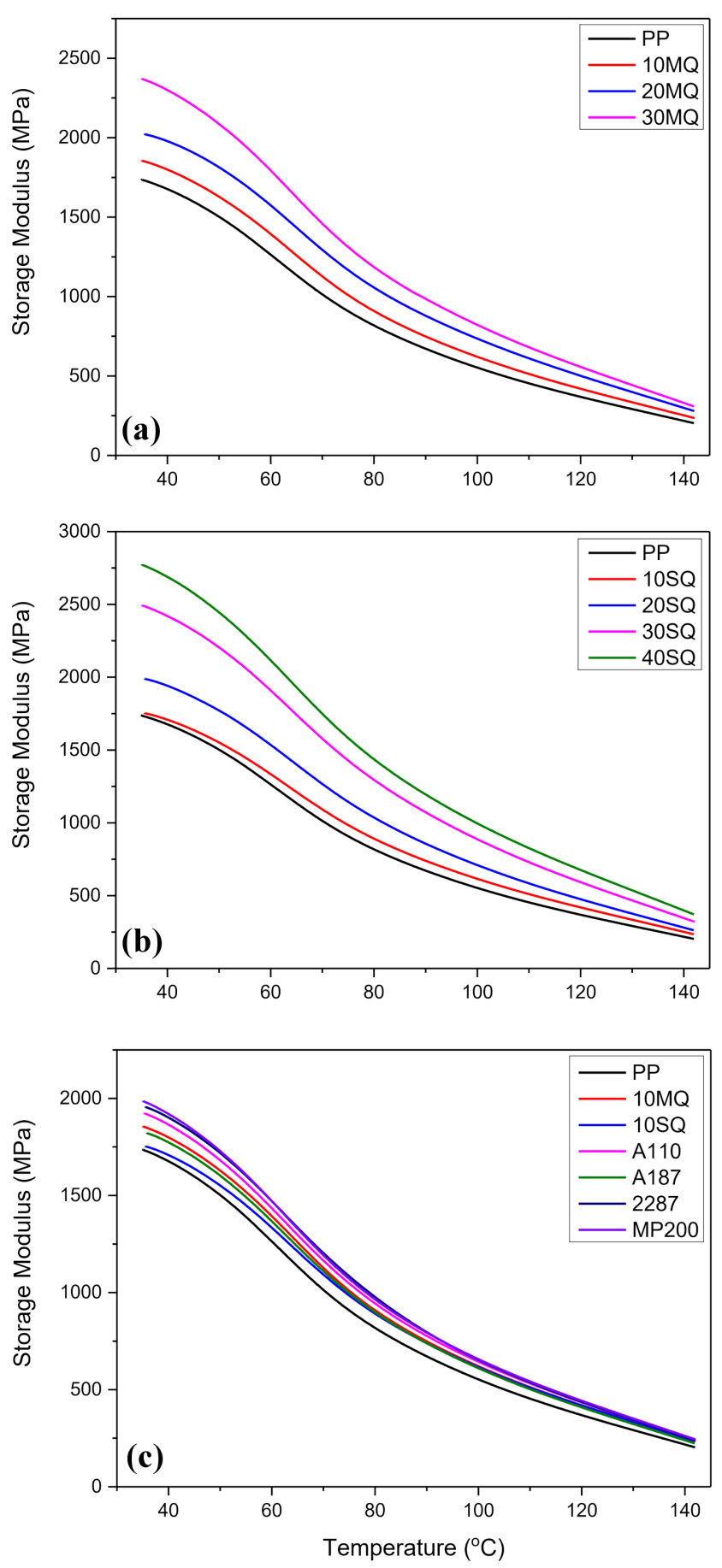

Fig. 1. Storage modulus (E') of PP and (a) micronized quartz, (b) silanized quartz, (c) surface modified quartz reinforced composites. 
Comparing the PP and the SQ reinforced PP composites with different SQ weight fractions at temperatures from 37 to $125^{\circ} \mathrm{C}$, it is easy to find that the modulus of the composites containing $40 \mathrm{wt} \% \mathrm{SQ}$ was higher than the other specimens.

Variations in storage modulus of PP, 10MQ, 10SQ and the surface treated filler loaded composites versus temperature were shown in Fig. 1c. MP200 composite has
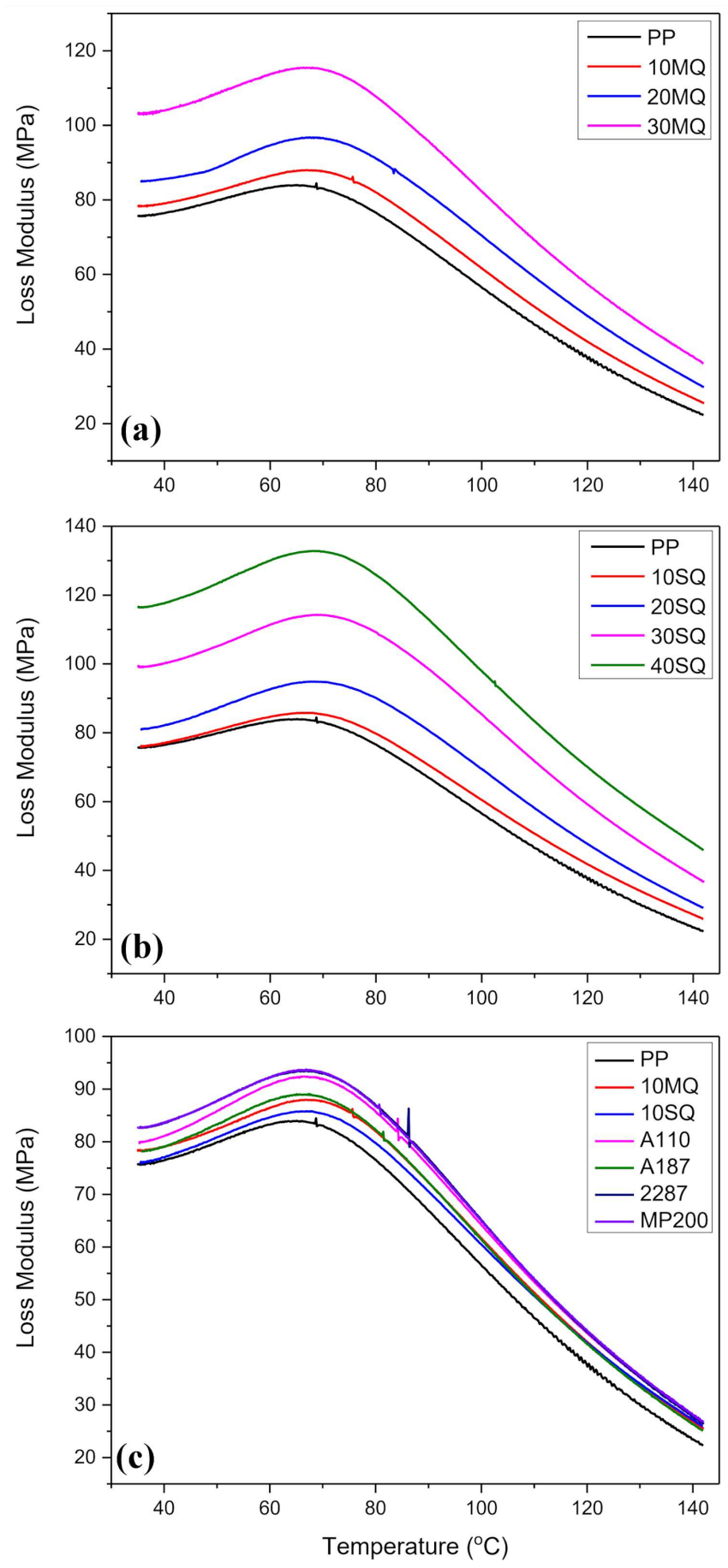

Fig. 2. Loss modulus $\left(E^{\prime \prime}\right)$ of PP and (a) micronized quartz, (b) silanized quartz, (c) surface modified quartz reinforced composites. the highest storage modulus value among all samples at $35{ }^{\circ} \mathrm{C}$. The storage modulus values of the all samples are decreased with increasing temperature because of an energy dissipation phenomenon [7].

Figure 2a shows the loss modulus values of PP and MQ-PP composites. Loss modulus $\left(E^{\prime \prime}\right)$ is a measure of viscous response of a material. It evaluates the energy dissipated as heat. As it is seen in Fig. 2, the $E^{\prime \prime}$ of all composites is higher than that of PP in the whole temperature range. This may be related to decrease in the flexibility of polymer by decreasing the segmental mobility of polymer [4]. The loss modulus continues to increase as MQ weight fraction increases. Samples (PP, 10MQ, 20MQ, and 30MQ) show $\alpha$-relaxation peaks at about $66.3,69.3,67.5$, and $68.0^{\circ} \mathrm{C}$, respectively. The $\alpha$-relaxation peak of PP increases after incorporation of MQ into PP. This may be attributed to higher viscous dissipation of the composites than that of polymer [8].

Figure $2 \mathrm{~b}$ represents the variations in the loss modulus of PP and SQ-PP composites. As was seen in Fig. 2b, the $E^{\prime \prime}$ of all composites is higher than that of PP in the entire temperature range. This may be related by decreasing the segmental mobility of polymer. It can be seen that the loss modulus increases after loading of SQ fillers into PP. Samples (PP, 10SQ, 20SQ, 30SQ, and 40SQ) show $\alpha$-relaxation peaks at about $66.3,67.8,68.4$, 69.0 and $68.9^{\circ} \mathrm{C}$, respectively. The $\alpha$-relaxation peak of $\mathrm{PP}$ increased after incorporation of $\mathrm{SQ}$ into $\mathrm{PP}$ due to higher viscous dissipation of the composites than that of polymer.

The variations in the loss modulus of PP, 10MQ, 10SQ and the surface treated filler loaded composites are shown in Fig. 2c. $E^{\prime \prime}$ of all composites is higher than that of PP in the all temperature range by decreasing the segmental mobility of polymer.

\section{Conclusion}

In this study, mechanical properties of micronized, silanized and surface modified quartz filled PP based composites were investigated. Elastic modulus of the composites increases as quartz weight fraction increases by 10 to $30 \%$. Fluxural strength and flexural modulus of the composites increases when quartz added. The loss and storage moduli increases with increasing quartz powders weight fraction. The mechanical properties of the composites produced with surface modified quartz powders show better results compared to micronized quartz added composites.

\section{References}

[1] J. Li, Appl. Surf. Sci. 255, 8682 (2009).

[2] B-X. Yang, J-H. Shi, K.P. Pramoda, S.H. Goh, Compos. Sci. Tech. 68, 2490 (2008).

[3] F. Ansari, M. Bazarganipour, M. Salavati-Niasari, Mater. Sci. Semicond.Process. 43, 34 (2016). 
[4] M. Garg, S. Sharma, R. Mehta, Compos. A Appl. Sci. Manuf. 76, 92 (2015).

[5] H.Y. Li, Y.Q. Tan, L. Zhang, Y.X. Zhang, Y.H. Song, Y. Ye, M.S. Xia, J. Hazard. Mater. 217, 256 (2012).

[6] L.F. Miranda, N.C. Pereira, S.B. Faldini, T.J. Masson, L.G.A. Silva, L.H. Silveira, in: 2009 International Nuclear Atlantic Conference.
[7] S. Thomas, K. Joseph, S.K. Malhotra, K. Goda, M.S. Sreekala, Polymer Composites, Macro- and Microcomposites, Rio de Janeiro 2009.

[8] M. Atagür, M. Sarikanat, T. Uysalman, O. Polat, İ.Y. Elbeyli, Y. Seki, K. Sever, J. Elastomers Plastics 50, 747 (2018). 